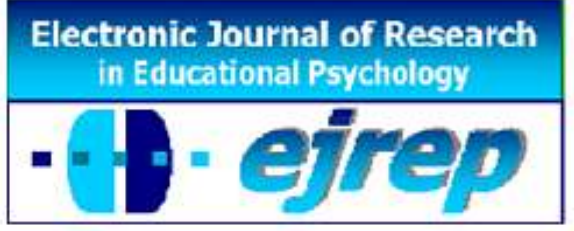

\title{
Validation of the Domains of Creativity Scale for Nigerian Preservice Science, Technology, and Mathematics Teachers
}

\author{
Adeneye O. A. Awofala ${ }^{1}$, Alfred O. Fatade ${ }^{2}$
}

${ }^{1}$ Department of Science and Technology Education, University of Lagos, Lagos

${ }^{2}$ Department of Mathematics, Tai Solarin University of Education, Ijagun

\section{Nigeria}

Correspondence: Adeneye O.A. Awofala. Department of Science and Technology Education, University of Lagos, Lagos. Nigeria. E-mail: aawofala@unilag.edu.ng

(C) Education \& Psychology I+D+i and Ilustre Colegio Oficial de la Psicología de Andalucía Oriental (Spain) 


\begin{abstract}
Introduction. Investigation into the factor structure of Domains of Creativity Scale has been on for sometimes now. The purpose of this study was to test the validity of the Kaufman Domains of Creativity Scale on Nigerian preservice science, technology, and mathematics teachers.
\end{abstract}

Method. Exploratory and confirmatory factor analyses were performed on the responses of 337 preservice science, technology, and mathematics teachers to the Kaufman Domains of Creativity Scale.

Results. Results of both analyses supported the five-factor structure of the Kaufman Domains of Creativity Scale: Mechanical/Scientific, Scholarly, Performance (encompassing writing and music), Self/Everyday, and Artistic. Construct validity of the Kaufman Domains of Creativity Scale was supported by its relationships with the Big Five Inventory in ways that were predicted by theory and consistent with previous research. Coefficient alphas and coefficients of congruence were generally strong.

Discussion and Conclusion. The present study provided incremental validity to the multidimensional nature of the Kaufman Domains of Creativity Scale thus reinforcing the five-factor model namely Mechanical/Scientific, Scholarly, Performance (encompassing writing and music), Self/Everyday, and Artistic. Additionally, a Nigerian version of the 50-item Kaufman Domains of Creativity Scale in the three major indigenous languages: Hausa, Igbo, and Yoruba need to created and tested among undergraduate and postgraduate students in Nigerian institutions of higher learning.

Keywords: creativity, creative self-perceptions, creative domains, validation.

Reception: 07/08/14 Initial acceptance: 10/23/14 Final acceptance: 03/10/15 


\section{Validación de una escala sobre dominios de creatividad para futuros profesores de ciencias naturales, tecnología y matemáticas}

\section{Resumen}

Introducción. La investigación sobre la estructura factorial de la Escala de Dominios de la Creatividad ha sido abundante hasta ahora . El propósito de este estudio fue probar la validez de las Esclas Kaufman de la Creatividad en una muestra de estudiantes de ciencia y tecnología, y matemáticas de pregrado nigeriana .

Método. Análisis factoriales exploratorios y confirmatorios se realizaron en las respuestas de los profesores de matemáticas de 337 alumnos de pregrado de ciencia y tecnología. Que contestaron a los dominios de la Escla Kaufman de Creatividad .

Resultados. Los resultados de ambos análisis apoyaron la estructura de cinco factores de los Dominios Kaufman de la Escla de Creatividad Escala: académica, de rendimiento (que abarca la escritura y la música) mecánica/científico, auto-percepción y Artístico. La validez de constructo de los dominios de la Escala Kaufman recibió el apoyo de sus relaciones con el inventario de los cinco grandes en formas que fueron predichas por la teoría y consistentes con investigaciones previas. Los coeficientes Alfa y de congruencia fueron generalmente altos.

Discusión y conclusión. El presente estudio proporciona validez incremental a la naturaleza multidimensional a la Escala de Dominios de la Creatividad Kaufman, reforzando así el modelo de cinco factores, académica, de rendimiento (que abarca la escritura y la música), a saber Mecánico / Científico, Auto-percepción y Artístico. Además, una versión nigeriana de la Escala de 50-item Kaufman de Dominios, en los tres principales idiomas indígenas (Hausa, Igbo, y Yoru-ba) es necesario crear y probar entre los estudiantes de pregrado y posgrado en las instituciones de educación superior de Nigeria.

Palabras Clave: creatividad, creativos auto-percepción, ámbitos creativos, validación.

$$
\text { Recibido: 07/08/14 Aceptación Inicial: 23/10/14 Aceptación final: 10/03/15 }
$$




\section{Introduction}

One major feature of a contemporary society is the rapid and complex change processes encircling all spheres of human existence and creativity has been recognised as a key factor for addressing the seemingly unending challenges orchestrated by these changes. Creativity is a powerful driving force for creating knowledge needed for the social and economic advancement of the society. The concept of creativity has traditionally proved indefinable and most of the main writers on creativity recognise a broad range of activity which can be termed as creative. Two major schools of thoughts are involved in the description of the concept of creativity. The first made distinction between "high" creativity and ordinary, everyday creativity. The second made distinction between creativity within specific domains and creativity as a separate process, applied within domains. Descriptions of creativity in this latter generic sense are more influential.

Torrance (1969) defined creativity broadly as the process of sensing a problem, searching for possible solutions, drawing hypotheses, testing and evaluating, and communicating the results to others. Torrance added that the process includes original ideas, a different point of view, breaking out of the mould, recombining ideas or seeing new relationships among ideas. Feldman, Cziksentmihalyi and Gardner (1994) defined creativity as "the achievement of something remarkable and new, something which transforms and changes a field of endeavour in a significant way. . . the kinds of things that people do that change the world" (p.1). Creativity is an 'exceptional human capacity for thought and creation' (Rhyammer \& Brolin, 1999, page 261). It is 'a person's capacity to produce new or original ideas, insights, restructurings, inventions or artistic objects, which are accepted by experts as being of scientific, aesthetic, social, or technological value' (Vernon, 1984, p.94). Creativity is 'the ability to produce new knowledge' (Dacey \& Lennon, 2000). The National Advisory Committee on Creative and Cultural Education (1999) defined creativity in ordinary or democratic sense as 'imaginative activity fashioned so as to yield an outcome that is of value as well as original' (p.29, para. 26). Seltzer \& Bentley (1999) said "creativity is the application of knowledge and skills in new ways to achieve a valued goal. To achieve this, learners must have four key qualities: - the ability to identify new problems, rather than depending on others to define them - the ability to transfer knowledge gained in one context to another in order to solve a problem - a belief in learning as an incremental process, in which repeated at- 
tempts will eventually lead to success - the capacity to focus attention in the pursuit of a goal, or set of goals' (p.10).

Aside the many conceptualisations/descriptions of creativity, the construct has been the subject of much experiential work from scholars, professionals, and policy makers ever since it was theoretically and operationally defined as a multi-dimensional construct. Hitherto, in spite of the considerable interest in the concept, yet little attention has been paid to creativity research in Nigeria. Within creativity research, the bone of contention has been whether domains exist or can creativity be thought of as single construct? Or is creativity domainspecific, with performance in different creative tasks poorly correlated with each other (Ivcevic, 2007)? A converging medium (Kaufman, 2012) has been the postulation of several models offering some general and some domain specific aspects (Baer \& Kaufman, 2005; Plucker \& Beghetto, 2004). Since most common measures of creativity are primarily domaingeneral (Torrance, 2008), with little domain specific measures, it is expedient to ask which are the key creative domains? (Kaufman, 2012). Nonetheless, this question addresses the very structure of creativity itself. Baer and Kaufman (2005) proposes the Amusement Park Theoretical (APT) model which is a hierarchical theory that presents domain-general preliminary needs for creativity such as a basic level of intelligence and motivation and domain-specific outcomes. The APT model provides general thematic areas such as writing or science, then domains such as poetry or fiction, and then microdomains such as Haikus or free verse (Kaufman, 2012).

Several studies have investigated the factor structure of creativity using reported behaviours, ratings, and self-assessments and most self-report creativity scales take a generalist perspective rather than focusing on specific domains. For instance, some of these scales emphasise idea generation (Runco, Plucker, \& Lim, 2001) or identity (Jaussi, Randel, \& Dionne, 2007) while others focus on creative activities such as the Biographical Inventory of Creative Behaviours (BICB; Batey, 2007), Creative Behaviour Inventory (CBI; Dollinger, 2006; Hocevar, 1979, 1980), Carson, Peterson, and Higgins' (2005) Creativity Achievement Questionnaire (CAQ). The Kaufman and Baer's (2004) Creativity Scale for Diverse Domains (CSDD) focuses on participants' opinion of their own opinions of creativity while Kaufman, Cole, and Baer (2009) developed the Creativity Domain Questionnaire which contained 56 different creative domains. 
The Kaufman Domains of Creativity Scale (K-DOCS) for this study was developed in 2012 by building on past work and used ratings of creative behaviours to analyse layperson perceptions of the structure of creativity (Kaufman, 2012). Being a self-report behaviourbased creativity rating scale, the K-DOCS reflects a domain specific perspective of everyday creativity. This scale needs significant further validation (Kaufman, 2012) and more imperative is to determine the consistency of its factor structure across cultures. Since the development of K-DOCS in 2012 little or no work has been carried out to cross-culturally validate the instrument among preservice teachers whose native language is not English. The present study has been conducted to fill up the empirical gap with regard to the psychometric soundness of the K-DOCS among the population of preservice STM teachers whose native language is not English.

Aims

Specifically, this study investigated the following research questions: (a) Would Kaufman's Domain of Creativity Scale be able to assess creativity among the population of preservice STM teachers in a Nigerian university? (b) Would Kaufman's Domain of Creativity Scale be able to demonstrate both construct validity as well as internal reliability when tested among preservice STM teachers whose native language is not English?

\section{Method}

\section{Participants}

The target population for this study was preservice STM teachers in three Nigerian Universities. The population size at the time of the study was two thousand one hundred and twenty (2120) students altogether. The sample size for preservice STM teachers was calculated based on Yamane's formula

$$
\begin{aligned}
& \mathrm{n}=\mathrm{N} /\left(1+\mathrm{Ne}^{2}\right) \text { where } \mathrm{n}=\text { sample size; } \\
& \mathrm{N}=\text { the size of population } \\
& \mathrm{e}=\text { the error of five percentage point. }
\end{aligned}
$$

Allowing for a plus/minus five (5) percent error rate, a sample size of three hundred and thirty seven (337) students was drawn from the population. The sample was stratified according to year of study (first to the fourth year) and disciplines. A disproportionate random 
sample was selected from each stratum. In the sample, 180 (53.4\%) studied science [90 (50\%) men and 90 (50\%) women], 100 (29.7\%) studied mathematics [50 (50\%) men and 50 (50\%) women], and 57 (16.9\%) studied technology [37 (64.9\%) men and 20 (35.1\%) women]. Altogether their ages ranged between 16 and 33 years $(\mathrm{M}=23.6, \mathrm{SD}=2.1)$. The science cohort comprised biology, chemistry, and physics preservice teachers. The technology cohort comprised woodwork technology, building technology, and auto-mechanic technology preservice teachers.

\section{Instruments}

Kaufman's Domain of Creativity Scale (K-DOCS). This scale is a 50-item instrument that measures creative behaviours of people (Kaufman, 2012). Each item is measured on a 5point Likert scale, with 1 being much less creative and 5 being much more creative. Instructions were as follows: "Compared to people of approximately your age and life experience, how creative would you rate yourself for each of the following acts? For acts that you have not specifically done, estimate your creative potential based on your performance on similar tasks.”. Kaufman (2012) reported internal consistency reliabilities of .86, .86, .87, .86, and .83 for Self/Everyday, Scholarly, Performance, Mechanic/Scientific, and Artistic as indicated by Cronbach's alpha, respectively. Kaufman (2012) also reported two weeks test retest reliabilities of $.80, .76, .86, .78$, and .81 for Self/Everyday, Scholarly, Performance, Mechanic/Scientific, and Artistic, respectively.

Big Five Personality Inventory: This is a 10 item short version of the Big Five Inventory adapted from Rammstedt and John (2007) measuring personality in one minute or less. The scale measures derived five-factor personality theory: Extraversion, Agreeableness, Conscientiousness, Emotional Stability, and Openness to Experience. In the Big Five Factor Markers, participants rate how well each statement describes themselves on a Likert scale from 1 (disagree strongly) to 5 (agree strongly). Sample statements include "I see myself as someone who is reserved," "I see myself as someone who is generally trusting," "I see myself as someone who tends to be lazy," "I see myself as someone who is relaxed, handles stress well," and "I see myself as someone who has an active imagination." The items were presented in a random order with positive and negative keying. For this sample, Cronbach's alpha reliabilities were as follows: Extraversion (.87), Agreeableness (.89), Conscientiousness (.84), Emotional Stability (.85), and Openness to Experience (.86). 


\section{Procedure}

The 50-item instrument of Kaufman Domain of Creativity Scale in the form of a selfreported questionnaire and the Big Five Personality Inventory were administered to the respondents during class hours. Permission was sought from the Heads of Departments to enable the researchers to administer the instrument in the classroom as well as to seek the cooperation of the instructors and students in completing the instrument during class hours. All in all a response rate of $100 \%$ was achieved. Analysis of the data collected was based on these fully completed $100 \%$ return rate.

\section{Data analysis}

The data collected were anlysed using exploratory and confirmatory factor analyses and Pearson Moment Correlation Coefficient. Prior to the analyses, the data in respect of the Kaufman Domains of Creativity Scale were screened for accuracy of data entry, missing values, normality, linearity, outliers, multi-collinearity and singularity, and factorability. Skewness statistics of all measures ranged from -1.16 to 1.42 . Kurtosis statistics ranged from -1.04 to .82 in the preservice STM teachers. More so, the appropriateness of the data for the factor analysis was analysed using Kaiser-Meyer-Olkin (KMO) and Bartlett Sphericity test. KMO value of the scale was found to be 0.87 . This showed that data were appropriate for the factor analysis (Leech, Barrett and Morgan, 2005). Bartlett's Sphericity test was made to verify that the data have multi-variable normal distribution (Tavşanc1l, 2002). The Kaiser's measure of sampling adequacy (MSA) fell within acceptable range (values of .60 and above) with a value of .756. Each of the variables also exceeded the threshold value (.60) of MSA. Lastly, most of the partial correlations were small as indicated by the anti-image correlation matrix. These measures all led to the conclusion that the set of 50 items of Kaufman Domains of Creativity Scale was appropriate for principal components/exploratory factor analyses (PCA/EFA). Factor analysis has two major types: exploratory and confirmatory. Exploratory factor analysis (EFA) is used to find the underlying factors of an assessment tool (Hair, Black, Babin, Anderson, \& Tatbam, 2006) while confirmatory factor analysis (CFA) is used to assess the fit of the model to the data (Brown, 2006). However, EFA was deemed necessary in this study, because there is no sufficient theoretical support for Kaufman Domains of Creativity Scale (Kaufman, 2012) in prior validation studies to present it as an a priori theory knowing full that it is a new scale. Confirmatory factor analysis (CFA) was used to assess the fit of the K-DOCS model to the data. 


\section{Results}

\section{Principal Components Analyses}

Principal components analyses were carried out on the responses of the sample to the 50 items of Kaufman Domains of Creativity Scale to establish their underlying dimensions. The initial unrotated PCA produced a factor model of five dimensions as indicated by the scree plot and eigenvalues greater than unity. This unrotated factor model was theoretically less meaningful and hence difficult to interpret. Thereafter, the analysis advanced to rotate the factor matrix both orthogonally and obliquely with Kaiser normalisation to achieve a simple and theoretically more meaningful solution. Varimax rotation was adopted for the orthogonal solution and oblimin rotation was used for the oblique solution. The two rotations produced a factor model of five dimensions as indicated by the scree plot (Figure 1) and eigenvalues greater than unity and no remarkable differences were observed between the orthogonal solution and the oblique solution in terms of factor structure and pattern of factor loadings. However, the oblique solution was retained because the correlation between the first and the fifth factor was .32 as indicated by the factor correlation matrix.

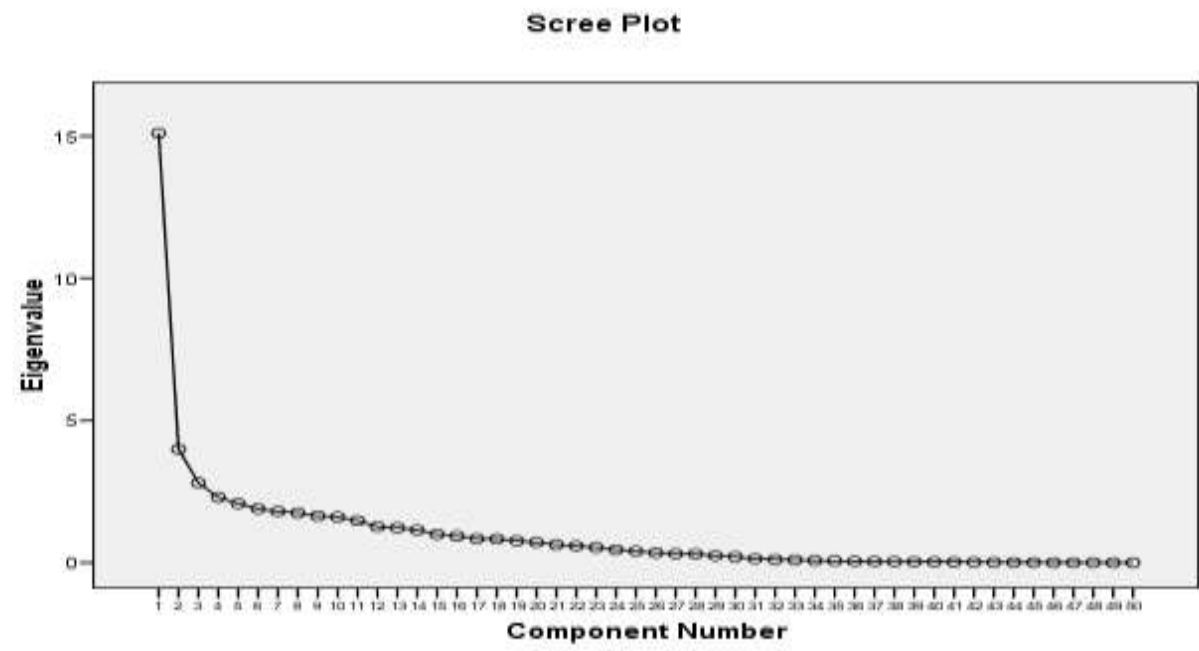

Figure 1. Cattell scree plot showing number of components and eigenvalues of the correlation matrix

Table 1 displays the factor loadings for the oblique five-factor model of Kaufman Domains of Creativity Scale. All items loaded .45 and above on their primary factor. All the five subscales combined explained $52.545 \%$ of the variance. The first factor accounted for 
$30.202 \%$ of the variance (eigenvalue $=15.101$ ) and consisted of 9 mechanic/scientific Kaufman Domains of Creativity Scale items. The second factor accounted for $7.982 \%$ of the variance (eigenvalue=3.991) and consisted of 11 scholarly Kaufman Domains of Creativity Scale items. The third factor accounted for $5.606 \%$ of the variance (eigenvalue=2.803) and consisted of 10 performance Kaufman Domains of Creativity Scale items. The fourth factor accounted for $4.591 \%$ of the variance (eigenvalue=2.296) and consisted of 9 self/everyday Kaufman Domains of Creativity Scale items. The fifth factor accounted for $4.164 \%$ of the variance (eigenvalue $=2.082$ ) and consisted of 9 artistic Kaufman Domains of Creativity Scale items. The five subscales can be said to be psychometrically stable and have exhibited both convergent and discriminant validity.

Table 1. Summary of Factor Loadings by Principal Component Analysis for the Oblique FiveFactor Model of Kaufman Domains of Creativity Scale

\begin{tabular}{lllllll}
\hline Items & & \multicolumn{3}{c}{ Factor Loadings } \\
& 1 & 2 & 3 & 4 & 5 \\
\hline
\end{tabular}

1. Carving something out of wood or similar material

2. Figuring out how to fix a frozen or buggy computer

3. Writing a computer program

4. Solving math puzzles

5. Taking apart machines and figuring out how they work

6. Building something mechanical (like a robot)

7. Helping to carry out or design a scientific experiment

8. Solving an algebraic or geometric proof

9. Constructing something out of metal, stone, or similar

Material

10. Writing a nonfiction article for a newspaper, newsletter, or magazine

11. Writing a letter to the editor

12. Researching a topic using many different types of sources that may not be readily apparent

13. Debating a controversial topic from my own perspective

14. Responding to an issue in a context-appropriate way

15. Gathering the best possible assortment of articles or papers to support a specific point of view

16. Arguing a side in a debate that I do not personally agree

17. Analyzing the themes in a good book

18. Figuring out how to integrate critiques and suggestions while revising a work

19. Being able to offer constructive feedback based on my 
20. Coming up with a new way to think about an old debate $\quad .75$

$\begin{array}{ll}21 . \text { Writing a poem } & .77\end{array}$

22. Making up lyrics to a funny song $\quad .73$

23. Making up rhymes $\quad .74$

$\begin{array}{ll}\text { 24. Composing an original song } & .74\end{array}$

25. Learning how to play a musical instrument $\quad .69$

26. Shooting a fun video to air on YouTube $\quad .63$

$\begin{array}{ll}\text { 27. Singing in harmony } & .71\end{array}$

28. Spontaneously creating lyrics to a rap song $\quad .78$

29. Playing music in public $\quad .78$

30. Acting in a play $\quad .76$

31. Finding something fun to do when I have no money $\quad .64$

32. Helping other people cope with a difficult situation $\quad .63$

33. Teaching someone how to do something $\quad .74$

34. Maintaining a good balance between my work and my personal life $\quad .79$

35. Understanding how to make myself happy $\quad .78$

36. Being able to work through my personal problems in a healthy way $\quad .77$

37. Thinking of new ways to help people $\quad .62$

38. Choosing the best solution to a problem $\quad .56$

39. Planning a trip or event with friends that meets everyone's needs $\quad .66$

40. Mediating a dispute or argument between two friends $\quad .68$

41. Getting people to feel relaxed and at ease $\quad .71$

42. Drawing a picture of something I've never actually seen

(like an alien) $\quad .56$

43. Sketching a person or object $\quad .60$

44. Doodling/drawing random or geometric designs $\quad .56$

45. Making a scrapbook page out of my photographs 4

46. Taking a well-composed photograph using an interesting

angle or approach $\quad .54$

$\begin{array}{ll}\text { 47. Making a sculpture or piece of pottery } & .58\end{array}$

48. Appreciating a beautiful painting $\quad .48$

49. Coming up with my own interpretation of a classic work

of art $\quad .52$

50. Enjoying an art museum $\quad .47$

Note. Factor 1= Mechanic/Scientific, Factor 2=Scholarly, Factor 3=Performance, Factor 4= Self/Everyday, Factor $5=$ Artistic.

\section{Confirmatory Factor Analyses}

Confirmatory factor analysis was conducted to analyze at which level a predetermined or designed structure would be confirmed by the collected data (Büyüköztürk et 
al., 2004). Through AMOS 18 confirmatory factor analysis, the items for each subscale of Kaufman Domains of Creativity Scale were examined for convergent validity and construct validity. All items were specified to load on only their respective factor and all factor loadings were estimated in the measurement model. Factor covariances were left free to be estimated, but the measurement errors were not allowed to covary. Results produced an inferential test of $\chi^{2}=1273.41(\mathrm{p}=.00 . \mathrm{df}=306)$ with the following descriptive fit indices (Root Mean Square Error of Approximation, RMSEA=.04 with 90\% CI=[.03-.05], Nonnormed Fit Index, NNFI or Tuker-Lewis Index, TLI=.95, and Comparative Fit Index, CFI=.95). The ratio $\chi^{2} / \mathrm{df}$ was less than 3 for an acceptable model fit. These results indicated that the five factor model of Kaufman Domains of Creativity Scale represents a good fit to the data. Table 2 showed the standardised factor loadings for this five factor model of the Kaufman Domains of Creativity Scale. The factor loadings ranged from .68 to .89 for the first factor, from .64 to .79 for the second factor, from .61 to .79 for the third factor, from .58 to .82 for the fourth factor, and from .45 to .65 for the fifth factor and all the factor loadings were statistically significant at 0.05 level of significance.

Table 2. Standardised Factor Loadings for the Five-Factor Model of Kaufman Domains of Creativity Scale

\begin{tabular}{|c|c|c|c|c|}
\hline \multirow[t]{2}{*}{ Items } & \multirow[b]{2}{*}{1} & \multirow[b]{2}{*}{2} & \multicolumn{2}{|r|}{ Factor Loadings } \\
\hline & & & 3 & 4 \\
\hline 1. Carving something out of wood or similar material & .70 & & & \\
\hline 2. Figuring out how to fix a frozen or buggy computer & .88 & & & \\
\hline 3. Writing a computer program & .89 & & & \\
\hline 4. Solving math puzzles & .86 & & & \\
\hline 5. Taking apart machines and figuring out how they work & .82 & & & \\
\hline 6. Building something mechanical (like a robot) & .87 & & & \\
\hline 7. Helping to carry out or design a scientific experiment & .88 & & & \\
\hline 8. Solving an algebraic or geometric proof & .87 & & & \\
\hline 9. Constructing something out of metal, stone, or similar & & & & \\
\hline Material & .88 & & & \\
\hline 10. Writing a nonfiction article for a newspaper, newsletter, & & & & \\
\hline or magazine & & .78 & & \\
\hline 11. Writing a letter to the editor & & .79 & & \\
\hline 12. Researching a topic using many different types of & & & & \\
\hline sources that may not be readily apparent & & .76 & & \\
\hline 13. Debating a controversial topic from my own perspective & & .69 & & \\
\hline 14. Responding to an issue in a context-appropriate way & & .64 & & \\
\hline
\end{tabular}


16. Arguing a side in a debate that I do not personally agree

with

17. Analyzing the themes in a good book

18. Figuring out how to integrate critiques and suggestions while revising a work

19. Being able to offer constructive feedback based on my own reading of a paper

20. Coming up with a new way to think about an old debate

.76

29. Playing music in public

31. Finding something fun to do when I have no money

33. Teaching someone how to do something

36. Being able to work through my personal problems in a healthy way

37. Thinking of new ways to help people

39. Planning a trip or event with friends that meets everyone's needs

41. Getting people to feel relaxed and at ease

45. Making a scrapbook page out of my photographs

48. Appreciating a beautiful painting

of art 
Note. Factor 1= Mechanic/Scientific, Factor 2=Scholarly, Factor 3=Performance, Factor 4= Self/Everyday, Factor $5=$ Artistic.

Two additional CFAs were carried out to evaluate the fit of the five-factor model of Kaufman Domains of Creativity Scale with two alternative models: (1) the four-factor model in which self/everyday, scholarly, and performance items load on their respective factors whereas the mechanic/scientific and artistic items were collapsed to load on one factor, and (2) the three-factor model in which self/everyday and scholarly items load on their respective factors whereas the performance, mechanic/scientific, and artistic items were collapsed to load on one factor. Table 3 showed the fit indices for the three- and four-factor models compared to the five-factor model. However, none of the alternative models showed a satisfactory overall fit. The five-factor model had the lowest Akaike Information Criterion (AIC) value, suggesting that it is only the best fitted model to the data and the most parsimonious model. All of the t-values of items showed statistical significance at the 0.05 level. This indicated that all of those items within each scale were highly correlated with each other and, so, revealed convergent validity.

Table 3. The Fit Indices for the Alternative Models of Kaufman Domains of Creativity Scale Compared to the Five-Factor Model

Model $\chi^{2} \quad$ df $\quad$-value $\quad$ RMSEA NNFI CFI AIC

\begin{tabular}{llllllll}
\hline Model 1 & 1273.41 & 306 & .000 & .04 & .95 & .95 & 305.46 \\
Model 2 & 1693.54 & 314 & .000 & .05 & .86 & .87 & 323.74 \\
Model 3 & 1703.54 & 314 & .000 & .06 & .80 & .83 & 601.76 \\
\hline \multicolumn{2}{l}{ Model Comparisons } & & $\Delta \chi^{2}$ & $\Delta$ df & \multicolumn{3}{c}{ p-value }
\end{tabular}

\begin{tabular}{lccc}
\hline Model 1 vs. 2 & 420.13 & 8 & $<.001$ \\
Model 1 vs. 3 & 430.13 & 8 & $<.001$
\end{tabular}

Note. Model 1= five-factor, Model 2= three-factor, Model 3= four-factor

\section{Correlational and Reliability Analyses}

To establish construct validity of the scales' scores, the Kaufman Domains of Creativity Scales were correlated with the Big Five Inventory in ways that were predicted by theory and 
consistent with the previous research. Table 4 showed the zero-order correlations between the five subscales of Kaufman Domains of Creativity Scale and five dimensions of the Big Five Inventory.

Table 4. Zero-order correlations between the five-factors of Kaufman Domains of Creativity Scale and Big Five Inventory

\begin{tabular}{llllllllllll}
\hline Variable & 1 & 2 & 3 & 4 & 5 & 6 & 7 & 8 & 9 & 10
\end{tabular}

\begin{tabular}{|c|c|c|c|c|c|c|c|c|c|}
\hline 1 & - & & & & & & & & \\
\hline 2 & .05 & - & & & & & & & \\
\hline 3 & .00 & $.14^{*}$ & - & & & & & & \\
\hline 4 & .05 & .03 & -.04 & - & & & & & \\
\hline 5 & $.10 *$ & .04 & .04 & .07 & - & & & & \\
\hline 6 & $.20 *$ & $.14^{*}$ & $.25^{*}$ & .01 & .02 & - & & & \\
\hline 7 & -.04 & $.11 *$ & $.41 *$ & $-.15^{*}$ & .07 & $.41^{*}$ & - & & \\
\hline 8 & $-.12^{*}$ & $.13^{*}$ & $.20 *$ & .02 & .03 & $.18^{*}$ & $.43^{*}$ & - & \\
\hline 9 & .03 & .02 & .09 & $.14 *$ & .03 & $.31 *$ & $.35^{*}$ & $.26^{*}$ & - \\
\hline 10 & $.16^{*}$ & $.45^{*}$ & $.30 *$ & .04 & $.18^{*}$ & $.41^{*}$ & $.53^{*}$ & $.44^{*}$ & $.26^{*}$ \\
\hline
\end{tabular}

Note. 1= Self/Everyday, 2=Scholarly, 3=Performance, 4=Mechanic/Scientific, 5= Artistic, 6=Extraversion, $7=$ Agreeableness, $8=$ Conscientiousness, $9=$ Emotional Stability, and 10=Openness to Experience, ${ }^{*} \mathrm{p}<.001$

As can be seen in Table 4, openness to experience significantly correlated with all creativity domains but Mechanical/Scientific. Extraversion significantly correlated with all domains and not Mechanical/Scientific and Artistic. Agreeableness and conscientiousness were both positively correlated with Scholarly and Performance but negatively correlated with Mechanical/Scientific and Self/Everyday, respectively. Emotional stability was the least related to creativity, with only a significant positive relationship with Mechanical/Scientific. For the present study, the internal consistency reliabilities of $.87, .87, .88, .85$, and .80 for Self/Everyday, Scholarly, Performance, Mechanic/Scientific, and Artistic as indicated by Cronbach's alpha were computed, respectively. The internal consistency reliability of 0.86 for the entire scale as expressed by Cronbach's alpha was computed. The two weeks test- retest reliabilities of $.84, .81, .77, .87, .77$, and .78 for the entire scale, Self/Everyday, Scholarly, Performance, Mechanic/Scientific, and Artistic were computed, respectively. All the subdomains showed acceptable internal consistency reliability and test-retest reliability. 


\section{Discussion and Conclusions}

The purpose of the study was to evaluate the psychometric properties of Kaufman Domains of Creativity Scale among preservice STM teachers at three Nigerian universities. All the 50 items that were employed to assess the domains of creativity phenomenon were found to load on 5 interpretable factors. The results of running an exploratory factor analysis yielded a 5-factor solution with the following sub-scales: Mechanical/Scientific (9 items), Scholarly (11 items), Performance (10 items) (encompassing writing and music), Self/Everyday (11 items), and Artistic (9 items). This finding supported that of previous study that had shown Mechanical/Scientific, Scholarly, Performance (encompassing writing and music), Self/Everyday, and Artistic to be indeed constructs that were distinguishable from one another (Kaufman, 2012). Kaufman's pioneering psychometric effort at creating a multidimensional scale resulted in a five factor solution in which the Self/Everyday subscale had the highest variance explained. The findings from the present study also demonstrated a 5-factor solution. However, the amount of variance explained by all the 5 factors was higher for Mechanical/Scientific. The fact that the same number of factors were yielded by this study provided incremental validity to the multidimensional nature of the Kaufman Domains of Creativity construct

A measure is said to be psychometrically stable and sound if it exhibits not only convergent and discriminant validity but internal reliability as well. For this study, two methods of determining a measure's internal reliability have been used; Cronbach alpha reliability coefficient as well as test-retest reliability coefficient. In the present study, coefficient alphas and coefficients of congruence were generally strong. Each of the sub-scale was subsequently examined for internal reliability and was found to have met the criteria of 0.70 as recommended by Nunnally and Bernstein (1994). Additionally, all the 50 items were then examined for internal reliability estimate and was found to have a Cronbach's internal reliability coefficient alpha value of 0.87 which met the recommended value of 0.70 as suggested by Nunnally and Bernstein (1994). Items for each of the sub-scale were again examined for construct validation by employing item to total score correlations. Each of the items in the 5 sub-scales was found to correlate very significantly (at $\mathrm{p}<.01$ ) with the total score for that sub-scale. The correlation coefficients for each of the item in the respective sub-scales reflect the factor loading coefficients that were yielded as a result of running a principal component exploratory factor 
analysis. Thus, efforts to triangulate the findings of construct validation using item to total score correlations was successful. In addition, the correlations between the five creativity domains and the five personality factors were consistent with past research, lending some evidence of construct validity (Kaufman, 2012).

In fact, openness to experience correlated with four of the five creativity domains, which was in line with previous studies (Kaufman, 2012; King, Walker, \& Broyles, 1996). The only domain that did not correlate with openness to experience was Mechanical/Scientific, in conformity with the Silvia et al. (2009) findings. In addition, Mechanical/Scientific was significantly negatively correlated with agreeableness (Kaufman, 2012; Silvia, Kaufman, Reiter-Palmon, \& Wigert, 2011) and positively correlated with emotional stability (Silvia et al., 2009), while Performance was significantly correlated with extraversion (Kaufman, 2012; Kaufman, Cole, \& Baer, 2009; Silvia, Kaufman, \& Pretz, 2009). In addition, the model fit index of the five factor framework of Kaufman Domains of Creativity Scale was significantly superior to that of all of the other alternative frameworks of Kaufman Domains of Creativity Scale considered. Thus, from a theoretical view point, these findings lend credence to the five factor conceptualisation of Kaufman Domains of Creativity Scale (Kaufman, 2012). The present study provided incremental validity to Kaufman's (2012) study in that the same sub-scale turned out to be the best predictor of the Domains of Creativity phenomenon. Another major finding in this study was that the preservice STM teachers scored higher on the Mechanical/Scientific subscale of K-DOCS. This finding agreed with the conjecture that specific populations should score higher on different domains (i.e. scientists should score higher on Mechanical/Scientific) (Kaufaman, 2012). This study is yet to verify the postulation that people with higher scores on the K-DOCS domains should theoretically score higher on objective tests in these areas.

This study suggested that the cross-cultural evidence of the Kaufman Domains of Creativity Scale's psychometric soundness and stability can also be assessed using postgraduate students as the sample. Would a 5-factor solution be found when the scale is tested amongst a population of postgraduate students whose native language is not English? Would the factor "Mechanical/Scientific" still explain the greatest proportion of variance in the Kaufman Domains of Creativity Scale? Would the scale also demonstrate internal reliability when applied amongst a population of postgraduate students whose native tongue is not English? Additionally, a Nigerian version of the 50-item Kaufman Domains of Creativity Scale in the three ma- 
jor indigenous languages: Yoruba, Hausa, and Igbo need to be created and tested among undergraduate and postgraduate students in Nigerian institutions of higher learning. More psychometric efforts are required before one can carefully conclude that Kaufman Domains of Creativity Scale is psychometrically sound and stable when applied in a cross-cultural environment where the population's native language is not English.

\section{References}

Baer, J., \& Kaufman, J. C. (2005). Bridging generality and specificity: The amusement park theoretical (APT) model of creativity. Roeper Review, 27, 158-163. doi:10.1080/02783190509554310.

Batey, M. (2007). A psychometric investigation of everyday creativity (Unpublished doctoral dissertation). University College, London, UK.

Brown, T.A. (2006). Confirmatory factor analysis for applied research. New York: Guilford.

Büyüköztürk, Ş., Akgün, Ö. E., Özkahveci, Ö., \& Demirel, F. (2004). The validity and reliability study of the Turkish version of the motivated strategies for learning questionnaire. Kuram ve Uygulamada Eğitim Bilimleri / Educational Sciences: Th eory \& Practice, 4(2), 231-239.

Carson, S., Peterson, J. B., \& Higgins, D. M. (2005). Reliability, validity and factor structure of the Creative Achievement Questionnaire. Creativity Research Journal, 17, 37-50. doi:10.1207/s15326934crj1701_4

Dollinger, S. J. (2006). Autophotographic individuality predicts creativity: A seven-year follow-up. Journal of Creative Behavior, 40, 111-124. doi:10.1002/j.21626057.2006.tb01268.x

Feldman, D.H, Czikszentmihalyi, M, \& Gardner, H. (1994). Changing the world, a framework for the study of creativity, Praeger Publishers, Westport, Connecticut, London, 1994.

Hair, J.F., Black, W.C., Babin, B.J., Anderson, R.E., \& Tatbam, R.L. (2006). Multivariate data analysis (6th ed.). New Jersey: Pearson.

Hocevar, D. (1979, April). The development of the Creative Behavior Inventory (CBI). Paper presented at the annual meeting of the Rocky Mountain Psychological Association, Las Vegas, NV: (ERIC Document Reproduction Service No. ED 170 350) 
Hocevar, D. (1980). Intelligence, divergent thinking, and creativity. Intelligence, 4, 25-40. doi:10.1016/0160-2896(80)90004-5

Ivcevic, Z. (2007). Artistic and everyday creativity: An act-frequency approach. Journal of Creative Behavior, 41, 271-290. doi:10.1002/j .2162-6057.2007.tb01074.x

Jaussi, K. S., Randel, A. E., \& Dionne, S. D. (2007). I am, I think I can, and I do: The role of personal identity, self-efficacy, and cross-application of experiences in creativity at work. Creativity Research Journal, 19, 247-258. doi:10.1080/10400410701397339.

Kaufman, J. C. (2012). Counting the Muses: Development of the Kaufman Domains of Creativity Scale (K-DOCS), Psychology of Aesthetics, Creativity, and the Arts, 6, 1-11 DOI: $10.1037 / \mathrm{a} 002975$

Kaufman, J. C., Cole, J. C., \& Baer, J. (2009). The construct of creativity: A structural model for self-reported creativity ratings. Journal of Creative Behavior, 43, 119-134. doi:10.1002/j.2162-6057.2009.tb01310.x

King, L. A., Walker, L. M., \& Broyles, S. J. (1996). Creativity and the five-factor model. Journal of Research in Personality, 30, 189-203. doi:10.1006/jrpe.1996.0013

Leech, N. L., Barrett, K. C., \& Morgan, G. A. (2005). SPSS for intermediate statistics; use and interpretation (2nd Edt.). Mahwah, NJ: Lawrence Erlbaum Associates.

National Advisory Committee on Creative and Cultural Education (NACCCE) (1999). All our futures:creativity, culture and education, Department for Education and Employment, London.

Nunnally, J., \& Bernstein, I. (1994). Psychometric theory (3rd ed.). New York: McGraw-Hill.

Plucker, J. A., \& Beghetto, R. A. (2004). Why creativity is domain general, why it looks domain specific, and why the distinction doesn't matter. In R. J. Sternberg, E. L. Grigorenko, \& J. L. Singer (Eds.), Creativity: From potential to realization (pp. 153167). Washington, DC: American Psychological Association. doi:10.1037/10692-009

Rammstedt, B. \& John, O. P. (2007). Measuring personality in one minute or less: A 10 item short version of the Big Five Inventory in English and German. Journal of Research in Personality, 41, 203-212.

Runco, M. A., Plucker, J., \& Lim, W. (2001). Development and psychometric integrity of a measure of ideational behavior. Creativity Research Journal, 13, 393-400. doi:10.1207/S15326934CRJ1334_16

Ryhammar, L. \& Brolin, C. (1999). Creativity research: historical considerations and main lines of development' in Scandinavian Journal of Educational Research, 43(3), 259273. 
Seltzer, K. \& Bentley, T. (1999). The creative age: knowledge and skills for the new economy, Demos, London.

Silvia, P. J., Kaufman, J. C., \& Pretz, J. E. (2009). Is creativity domainspecific? Latent class models of creative accomplishments and creative self-descriptions. Psychology of Aesthetics, Creativity, and the Arts, 3, 139-148. doi:10.1037/a0014940

Silvia, P. J., Nusbaum, E. C., Berg, C., Martin, C., \& O’Conner, A. (2009). Openness to experience, plasticity, and creativity: Exploring lowerorder, higher-order, and interactive effects. Journal of Research in Personality, 43, 1087-1090.

Silvia, P. J., Wigert, B., Reiter-Palmon, R., \& Kaufman, J. C. (2012). Assessing creativity with self-report scales: A review and empirical evaluation. Psychology of Aesthetics, Creativity, and the Arts, 6, 19-34. doi:10.1037/a0024071

Tavşancil, E. (2002) Tutumlarin ölçülmesi ve spss ile veri analizi. Ankara: Nobel Yayinlari. [In Turkish].

Torrance, E. P. (1969). Prediction of adult creative achievement among high school seniors. Gifted Child Quarterly, 13, 223-229.

Torrance, E. P. (2008). The Torrance Tests of Creative Thinking Norms-Technical Manual Figural (Streamlined) Forms A \& B. Bensenville, IL: Scholastic Testing Service.

Vernon, P.E. (1989). The nature-nurture problem in creativity' in J. A.Glover, R. R. Ronning \& C. R. Reynolds (eds). Handbook of creativity: perspectives on individual differences, Plenum Press, New York, NY. 